Pesq. Vet. Bras. 28(9):431-436, setembro 2008

\title{
Metabolismo oxidativo dos neutrófilos de bezerros das raças Nelore e Limousin nos primeiros quatro meses de vida ${ }^{1}$
}

\author{
Márcio Carvalho da Costa ${ }^{2}$, Karina Keller Marques da Costa Flaiban², Mariana \\ Marcantonio Coneglian ${ }^{3}$, Romerson Dognani ${ }^{3}$, Evandro Doine Vettorato ${ }^{3}$, \\ Mara Regina Stipp Balarin ${ }^{4}$ e Júlio Augusto Naylor Lisbôa ${ }^{5^{\star}}$
}

\begin{abstract}
Costa M.C., Flaiban K.K.M.C., Coneglian M.M., Dognani R., Vettorato E.D., Balarin M.R.S. \& Lisbôa J.A.N. 2008. [Neutrophil oxidative burst in Nelore and Limousin calves in the first four months of life.] Metabolismo oxidativo dos neutrófilos de bezerros das raças Nelore e Limousin nos primeiros quatro meses de vida. Pesquisa Veterinária Brasileira 28(9):431-436. Departamento de Clínicas Veterinárias, Centro de Ciências Agrárias, Universidade Estadual de Londrina, Campus Universitário, Cx. Postal 6001, Londrina, PR 86051-990, Brazil. E-mail: janlisboa@uel.br

To study some defence mechanisms of beef calves kept on range conditions, 90 healthy calves, 45 Nelore and 45 Limousin, were bled at 24 to 36 hours of life, 15, 30, 60, 90 and, 120 days. Leukogram and neutrophil oxidative burst through the non-stimulated and the stimulated NBT tests were determined. The parasitemia with Anaplasma marginale, Babesia bigemina and B. bovis was investigated. Repeated measure ANOVA was used to analyse the age effect on leukocyte counts. Variation of positive neutrophil throughout the age was analysed through Krushkal-Wallis test. Comparisons among breeds were done using the Mann-Whithney test. The white blood cell count increased with age in both breeds, with a decrease in neutrophil and an increase in lymphocyte counts. The neutrophil lymphocyte ratio had been inverted before 15 days of life. The neutrophil oxidative burst was less effective in the newborn calves increasing with age. Limousin calves' neutrophils had higher capacity to reduce NBT in advanced ages. The observed differences between taurine and Zebu calves had no effects on calves' health and could be atributed to Anaplasma marginale natural and asynptomatic infection.
\end{abstract}

INDEX TERMS: Beef calf, Zebu, taurine, NBT, Anaplasma marginale.

RESUMO.- Com o objetivo de investigar alguns mecanismos de defesa em bezerros de raças de corte criadas a campo, foram utilizados 90 animais recém-nascidos aparentemente sadios, 45 da raça Nelore e 45 da raça

\footnotetext{
${ }^{1}$ Recebido em 10 de junho de 2008.

Aceito para publicação em 15 de setembro de 2008.

Dissertação de Mestrado do primeiro autor; apoio financeiro da CAPES, da Fundação Araucária (Proc.4662; Edital 05/2003) e do FAEPE/ PROPPG/UEL.

${ }^{2}$ Discente do Programa de Pós-Graduação em Ciência Animal, Universidade Estadual de Londrina (UEL).

${ }^{3}$ Acadêmico de Medicina Veterinária da UEL; bolsista de Iniciação Científica.

${ }^{4}$ Departamento de Medicina Veterinária Preventiva, Centro de Ciências Agrárias (CCA), UEL, Londrina, PR, Brasil.

${ }^{5}$ Departamento de Clínicas Veterinárias, CCA, UEL, Campus Universitário, Cx. Postal 6001, Londrina, PR 86051-990. *Autor para correspondência: janlisboa@uel.br
}

Limousin. Amostras de sangue foram colhidas de cada bezerro entre 24 e 36 horas de vida e aos 15, 30, 60, 90 e 120 dias. Determinaram-se o leucograma e o metabolismo oxidativo dos neutrófilos por meio do teste da redução do tetrazólio de nitroazul (NBT), provas não estimulada (NBT-NE) e estimulada (NBT-E). Investigou-se a taxa de parasitemia determinada por Anaplasma marginale, Babesia bigemina e $B$. bovis. Utilizou-se a análise de variância de medidas repetidas para estudar o comportamento das variáveis hematológicas com o avançar da idade. O teste de Krushkal-Wallis foi empregado para caracterizar a variação da porcentagem de neutrófilos reativos relacionada à idade. Comparações entre as raças foram realizadas em cada idade por meio do teste de MannWhithney. A contagem total de leucócitos aumentou com a idade nas duas raças estudadas. Observou-se diminuição do número de neutrófilos e aumento do de linfócitos, 
ocorrendo sua inversão antes dos 15 dias de idade. A capacidade oxidativa dos neutrófilos foi menor nos bezerros recém-nascidos e aumentou com o avançar da idade. Os neutrófilos dos bezerros Limousin apresentaram maior capacidade de redução do NBT do que os dos bezerros Nelore, notadamente após o segundo mês de vida. Essa diferença não provocou reflexos sobre a saúde dos animais e pode ser resultado da infecção natural e assintomática com o Anaplasma marginale.

TERMOS DE INDEXAÇÃO: Bezerro de corte, zebuínos, taurinos, NBT, Anaplasma marginale.

\section{INTRODUÇÃO}

O organismo dos animais conta com vários mecanismos de defesa, entre eles, a fagocitose dos agentes invasores, que pode ser realizada por dois sistemas complementares: o mielóide e o mononuclear-fagocitário. Os neutrófilos correspondem a cerca de $20-30 \%$ dos leucócitos circulantes nos ruminantes e representam o principal grupo celular do sistema mielóide. A destruição de microrganismos pelos neutrófilos ocorre por meio de dois mecanismos: a explosão respiratória e a liberação de enzimas líticas e de peptídeos antimicrobianos presentes nos grânulos intracelulares (Tizard 2002).

Existem vários métodos para a avaliação do metabolismo oxidativo dos neutrófilos. Dentre eles, a redução do tetrazólio de nitroazul (NBT) é um dos mais indicados (Gordon et al. 1975). O NBT é um corante que é reduzido pelo ânion superóxido a um precipitado insolúvel de coloração azul-escuro conhecido como formazam (Park \& Good 1970). A presença desse precipitado no interior da célula confirma não somente a capacidade fagocitária do neutrófilo, mas também o seu potencial de reação oxidativa e, portanto, de atividade microbicida. Com o objetivo de aumentar a sensibilidade do método, Park \& Good (1970) propuseram o uso de um extrato bacteriano inativado para estimular a resposta dos neutrófilos ao teste do NBT. A esse teste deu-se o nome de NBT estimulado (NBT-E), chamando-se o teste com redução espontânea, de NBT não estimulado (NBT-NE).

Apesar da reconhecida importância do método em questão para o diagnóstico da doença granulomatosa crônica em crianças (Baehner \& Nathan 1968), poucos estudos foram desenvolvidos em outras espécies. Poli \& Mantelli (1974) e Hauser et al. (1986) demonstraram que a capacidade microbicida dos neutrófilos pode variar com a idade dos bezerros em seus primeiros meses de vida, apresentando, contudo, resultados conflitantes. No Brasil, pouco se estudou a respeito do metabolismo oxidativo dos neutrófilos de bezerros recém-nascidos de raças leiteiras (Peixoto et al. 2002, Costa et al. 2004) e de corte (Amorim 2002). Além disso, não há nenhuma comparação entre zebuínos e taurinos. Este estudo foi realizado com o objetivo de investigar o metabolismo oxidativo dos neutrófilos de bezerros de corte das raças Nelore e Limousin ao longo dos quatro primeiros meses de vida.

\section{MATERIAL E MÉTODOS}

Foram utilizados 45 bezerros da raça Limousin e 45 da raça Nelore, produtos de partos eutócicos e aparentemente sadios após o nascimento e ao longo do primeiro dia de vida. As duas propriedades localizadas na região norte do Paraná praticavam manejo extensivo sob condições naturais com bom padrão de manejos nutricional e sanitário. Durante todo o período do experimento, a observação dos animais era realizada duas vezes ao dia para a identificação de novos nascimentos e da manifestação de doenças ou outras alterações.

Os bezerros permaneceram junto às mães desde o nascimento e não foram auxiliados a mamar o colostro. Não houve nenhuma mudança no manejo e os animais não foram submetidos à vacinação até o término do experimento. A identificação individual, por tatuagem na raça Limousin e aplicação de brinco na raça Nelore, foi realizada no primeiro dia de vida logo após o curativo do umbigo com produto à base de iodofórmio, fenol, ácido pícrico e diclorvós (Umbicura $®)$ ).

As amostras de sangue foram obtidas por venopunção da jugular com o uso de agulhas 25x0,7mm (PrecisionGlide, BD) acondicionando-se em frascos a vácuo de $10 \mathrm{~mL}$ sem anticoagulante (Vacoum II, Labnew) e de $5 \mathrm{~mL}$ com anticoagulante EDTA 15\% (Vacoum II, Labnew). As colheitas foram realizadas seqüencialmente nas seguintes idades: 24-36 horas de vida, $15,30,60,90$ e 120 dias.

Imediatamente após a colheita, $500 \mu \mathrm{L}$ de sangue total foram retirados do frasco sem anticoagulante e transferidos para um tubo plástico com capacidade de $1,5 \mathrm{~mL}$ previamente preparado com $2 \mu \mathrm{L}$ de heparina sódica $(5000 \mathrm{UI} / \mathrm{mL})$ para a realização do teste da redução do NBT segundo Park \& Good (1970), modificado por Ciarlini et al. (1999). Alíquotas de $25 \mu \mathrm{L}$ do tetrazólio de nitroazul (Sigma-Aldrich, St Louis, EUA), previamente diluído (1 $\mathrm{mg}$ em $1 \mathrm{~mL}$ de água destilada), foram acondicionadas em tubos plásticos de $1,5 \mathrm{~mL}$. O corante permaneceu congelado a $20^{\circ} \mathrm{C}$ negativos e era descongelado momentos antes da realização do teste. Os procedimentos para a execução dos testes NBT-NE e NBT-E não excederam o tempo de duas horas após a colheita.

Para a prova não estimulada (NBT-NE), $25 \mu \mathrm{L}$ de sangue foram transferidos para o tubo contendo $25 \mu \mathrm{L}$ de NBT. Para o teste estimulado (NBT-E), 1,25 $\mu \mathrm{L}$ de extrato de bactérias (Stimulant, Sigma-Aldrich, St Louis, EUA) foram acrescentados ao tubo contendo os $25 \mu \mathrm{L}$ do NBT anteriormente à adição de $12,5 \mu \mathrm{L}$ de sangue. Após a homogeneização, os tubos permaneceram em repouso durante $15 \mathrm{~min}$ em banho-maria a $37^{\circ} \mathrm{C}$ e por mais $15 \mathrm{~min}$ à temperatura ambiente. Esfregaços sangüíneos foram confeccionados em triplicata para cada uma das provas, corados com May-Grünwald e Giemsa (Jain 1986) e posteriormente examinados ao microscópio óptico. A porcentagem de neutrófilos redutores ou reativos foi estabelecida através da contagem de 200 células, considerando-se como positivas aquelas que apresentaram em seu citoplasma a coloração enegrecida característica do NBT reduzido, conhecida como formazam.

Para a determinação do leucograma empregaram-se os métodos tradicionais em hematologia, com a contagem total de leucócitos em câmara de Neubauer e a contagem diferencial em extensões sangüíneas coradas (Jain 1986). A proporção de eritrócitos parasitados com Anaplasma marginale, Babesia bigemina e Babesia bovis foi investigada nas mesmas extensões sangüíneas identificando-se as formas intracitoplasmáticas características desses organismos (Hoffman 1987). Examina- 
ram-se, para tanto, 25 campos contendo em torno de 200 eritrócitos cada.

O teste de Krushkal-Wallis foi utilizado para caracterizar a variação da porcentagem de neutrófilos reativos relacionada à idade, considerando-se cada raça em separado. Comparações entre as raças foram realizadas em cada idade por meio do teste de Mann-Whithney. Para avaliar o comportamento das variáveis hematológicas com o avançar da idade empregou-se a análise de variância de medidas repetidas. No caso dos neutrófilos circulantes, os efeitos dos fatores raça e idade foram testados por meio da análise de variâncias de medidas repetidas bifatorial. Utilizou-se o teste de Tukey admitindo-se uma probabilidade de erro de 5\% (Curi 1998).

O projeto foi aprovado pelo Comitê de Ética em Experimentação Animal da Universidade Estadual de Londrina (CEEA/ UEL), registrado sob o número 14/05.

\section{RESULTADOS E DISCUSSÃO}

O número de leucócitos circulantes variou significativamente de acordo com a idade, observando-se aumento dessas células com valores mais altos a partir dos 90 dias de vida na raça Nelore e dos 60 dias na raça Limousin (Quadro 1). Em ambas as raças ocorreu diminuição do número de neutrófilos, que eram maioria após o nascimento, e aumento de linfócitos, sendo que aos 15 dias já havia ocorrido a inversão na proporção neutrófilo:linfócito. Tal comportamento está de acordo com outros resultados encontrados na literatura (LaMotte \& Ebehart 1976, Adams et al. 1992, Biondo et al. 1998, Fagliari et al. 1998, Menge et al. 1998, Peixoto et al. 2002). O número elevado de neutrófilos circulantes nos bezerros recém-nascidos parece estar relacionado com os altos níveis séricos de cortisol durante este período. A concentração do hormônio apresenta grande declínio nos primeiros dias de vida e continua a decair até aproximadamente 12 dias, acompanhada pela diminuição da contagem de neutrófilos (Ebehart \& Patt 1971, Benesi 1992).

Observou-se a maior contagem dos linfócitos circulantes nos bezerros da raça Nelore a partir dos 90 dias de idade. Os animais da raça Limousin apresentaram linfocitose a partir dos 60 dias de idade (Fagliari et al. 1998). A linfocitose fica evidente pela diminuição observada na relação neutrófilo:linfócito (Quadro 1), que nos bovinos, deve diminuir de 2,8 ao nascimento até 0,5 aos 5 dias de idade, permanecendo constante até a fase adulta (Taylor 2000). Segundo Birgel Júnior et al. (2001) esta condição poderia ser devida à premunição natural contra Anaplasma marginale e Babesia spp. encontrados nos bovinos criados a campo em regiões tropicais e subtropicais. Yoshihara (2001) relatou aumento de anticorpos contra Anaplasma marginale a partir dos 60 dias de idade em bezerros Nelore criados sob condições extensivas de manejo na região norte do Paraná.

De fato, ao longo do período experimental, foi possível observar infestações naturais com carrapatos nos bezerros estudados de ambas as raças, já a partir do primeiro mês de vida. Aparentemente, não se constatou distinção entre as raças e as infestações foram leves, de forma geral. Nos dois rebanhos o controle com produtos carrapaticidas somente era realizado em caso de necessidade para debelar infestações moderadas ou graves. Como seria de se esperar, infecções naturais e assintomáticas com hemoparasitas, foram comprovadas tanto nos taurinos quanto nos zebuínos (Quadro 2). A infecção com Anaplasma marginale foi particularmente consistente e a maioria dos bezerros estudados tornou-se portadora já aos 60 dias de

Quadro 2. Média de parasitemia (\% de eritrócitos parasitados) e número $(n)$ de bezerros aparentemente sadios das raças Nelore e Limousin portadores das infecções com Anaplasma marginale e com Babesia bigemina nos primeiros 120 dias de vida

\begin{tabular}{|c|c|c|c|c|c|c|c|c|}
\hline \multirow[t]{3}{*}{ Idade } & \multicolumn{4}{|c|}{ Anaplasma marginale } & \multicolumn{4}{|c|}{ Babesia bigemina } \\
\hline & Nelore & & Limousin & & Nelore & & Limousin & \\
\hline & Parasitemia & $n$ & Paras & $\bar{n}$ & rasitemia & $\mathrm{n}$ & nia & $\mathrm{n}$ \\
\hline & & 1 & & 2 & & & & \\
\hline & & 5 & & 6 & 6 & & 0 & \\
\hline & & 6 & & 1 & & & & \\
\hline & & 40 & & 3 & , & 2 & 0,001 & \\
\hline 90 & 0,1074 & 29 & 0,0 & 31 & 0,0026 & 4 & 0,0014 & 3 \\
\hline 120 dias & s $\quad 0,0276$ & 11 & 0,1039 & 38 & 0,0026 & 5 & 0,0036 & 8 \\
\hline
\end{tabular}

Quadro 1. Valores médios e desvios-padrão $(x \pm s)$ da contagem total de leucócitos (Leuco), neutrófilos segmentados (Seg) e linfócitos (Linfo) e da relação neutrófilo:linfócito (N:L) em bezerros sadios das raças Nelore e Limousin nos primeiros 120 dias de vida

\begin{tabular}{|c|c|c|c|c|c|c|}
\hline & 24 a $36 h$ & 15 dias & 30 dias & 60 dias & 90 dias & 120 dias \\
\hline & \multicolumn{6}{|c|}{ Nelore } \\
\hline $\begin{array}{l}\text { Leuco }\left(\times 10^{3} / \mathrm{mm}^{3}\right) \\
\text { Seg }\left(\times 10^{3} / \mathrm{mm}^{3}\right) \\
\text { Linfo }\left(\times 10^{3} / \mathrm{mm}^{3}\right) \\
\mathrm{N}: \mathrm{L}\end{array}$ & $\begin{array}{c}10,68^{\mathrm{c}} \pm 3,99 \\
6,75^{\mathrm{a}} \pm 3,53 \\
3,85^{\mathrm{d}_{ \pm}}, 12 \\
1,87^{\mathrm{a}} \pm 0,92\end{array}$ & $\begin{array}{c}11,37^{b c_{ \pm}} \pm 3,23 \\
4,09^{b c} \pm 1,80 \\
7,16^{c} \pm 2,07 \\
0,60^{b} \pm 0,26\end{array}$ & $\begin{array}{c}13,38^{a b} \pm 4,68 \\
4,68^{b} \pm 2,26 \\
8,58^{b} \pm 3,23 \\
0,57^{b} \pm 0,27\end{array}$ & $\begin{array}{c}11,78^{\mathrm{bc}} \pm 3,99 \\
3,03^{\mathrm{c}} \pm 1,72 \\
8,65^{\mathrm{b}} \pm 3,33 \\
0,38^{\mathrm{b}} \pm 0,22\end{array}$ & $\begin{array}{c}14,42^{a_{ \pm}} \pm 4,94 \\
3,12^{c} \pm 1,38 \\
11,13^{a_{ \pm}} \pm 3,96 \\
0,29^{c} \pm 0,13\end{array}$ & $\begin{array}{l}13,34^{a_{ \pm}}+64 \\
3,51^{b c_{ \pm 1}}, 75 \\
9,70^{a b} b_{ \pm 3,88} \\
0,40^{b c_{ \pm 0,23}}\end{array}$ \\
\hline $\mathrm{N}: \mathrm{L}$ & \multicolumn{6}{|c|}{ Limousin } \\
\hline $\begin{array}{l}\text { Leuco }\left(\times 10^{3} / \mathrm{mm}^{3}\right) \\
\text { Seg }\left(\times 10^{3} / \mathrm{mm}^{3}\right) \\
\text { Linfo }\left(\times 10^{3} / \mathrm{mm}^{3}\right) \\
\mathrm{N}: \mathrm{L}\end{array}$ & $\begin{array}{l}8,08^{b} \pm 3,20 \\
4,70^{a} \pm 0,44 \\
3,30^{d} \pm 1,19 \\
1,50^{a} \pm 0,70\end{array}$ & $\begin{array}{l}9,33^{b} \pm 3,03 \\
2,82^{b} \pm 1,70 \\
6,50^{c} \pm 1,89 \\
0,43^{b} \pm 0,22\end{array}$ & $\begin{array}{c}11,07^{\mathrm{b}} \pm 4,61 \\
1,82^{\mathrm{b}} \pm 1,09 \\
9,23^{\mathrm{b}} \pm 4,10 \\
0,22^{\mathrm{b}} \pm 0,14\end{array}$ & $\begin{array}{c}16,30^{a_{ \pm}} \pm 6,71 \\
2,04^{\mathrm{b}} \pm 1,39 \\
14,04^{\mathrm{a}} \pm 5,84 \\
0,15^{\mathrm{b}} \pm 0,09\end{array}$ & $\begin{array}{c}16,22^{\mathrm{a}_{ \pm}} \pm 6,41 \\
1,75^{\mathrm{b}} \pm 0,93 \\
13,66^{\mathrm{a}} \pm 5,47 \\
0,15^{\mathrm{b}} \pm 0,10\end{array}$ & $\begin{array}{c}17,92^{\mathrm{a}_{ \pm}} \pm 7,54 \\
2,58^{\mathrm{b}} \pm 3,40 \\
15,25^{\mathrm{a}} \pm 7,11 \\
0,28^{\mathrm{b}} \pm 0,92\end{array}$ \\
\hline
\end{tabular}

a, b, c Letras diferentes indicam diferença significativa $(p<0,05)$ entre as idades. 


\section{Quadro 3. Medianas das porcentagens de neutrófilos redutores do tetrazólio de nitroazul na prova não estimulada (NBT-NE) e na prova estimulada (NBT-E) em bezerros sadios das raças Nelore e Limousin nos primeiros 120 dias de vida}

\begin{tabular}{cccccc}
\hline \multirow{2}{*}{ Idade } & \multicolumn{2}{c}{ NBT-NE } & & \multicolumn{2}{c}{ NBT-E } \\
\cline { 2 - 3 } \cline { 5 - 6 } & Nelore & Limousin & & Nelore & Limousin \\
\hline $24-36$ horas & $2,5^{\mathrm{Aab}}$ & $2,0^{\mathrm{Ab}}$ & & $6,0^{\mathrm{Ac}}$ & $6,0^{\mathrm{Ab}}$ \\
15 dias & $2,0^{\mathrm{Ab}}$ & $2,75^{\mathrm{Ab}}$ & & $6,0^{\mathrm{Bc}}$ & $8,0^{\mathrm{Ab}}$ \\
30 dias & $2,0^{\mathrm{Bb}}$ & $4,0^{\mathrm{Aab}}$ & & $6,5^{\mathrm{Bc}}$ & $8,5^{\mathrm{Ab}}$ \\
60 dias & $3,0^{\mathrm{Aab}}$ & $4,0^{\mathrm{Aab}}$ & & $8,0^{\mathrm{Ab}}$ & $9,5^{\mathrm{Ab}}$ \\
90 dias & $3,0^{\mathrm{Ba}}$ & $5,0^{\mathrm{Aa}}$ & & $10,5^{\mathrm{Ba}}$ & $15,5^{\mathrm{Aa}}$ \\
120 dias & $2,0^{\mathrm{Bb}}$ & $5,0^{\mathrm{Aa}}$ & & $6,0^{\mathrm{Bc}}$ & $15,0^{\mathrm{Aa}}$
\end{tabular}

A, B Letras diferentes nas linhas indicam diferença significativa $(p<0,05)$ entre as raças em cada um dos testes.

$a, b$ Letras diferentes nas colunas indicam diferença significativa $(p<0,05)$ entre as idades.

idade. Hemácias parasitadas com $B$. bigemina foram detectadas em um número muito menor de bezerros. A infecção com $B$. bovis somente se confirmou em dois bezerros Nelore com 60 dias de vida e em três bezerros Limousin, um aos 30 dias e dois aos 90 dias de idade.

A capacidade oxidativa dos neutrófilos se elevou com o avançar da idade em ambas as raças estudadas (Quadro 3). O aumento na porcentagem de células redutoras do NBT foi mais evidente no teste do NBT-E, no qual se observou aumento significativo a partir do terceiro mês de idade. No entanto, essa capacidade voltou a diminuir aos 120 dias de vida nos animais da raça Nelore.

A menor capacidade em responder a estímulos encontrada nos neutrófilos de animais mais jovens, é coerente com as observações de outros autores (Hauser et al. 1986, Peixoto et al. 2002, Costa et al. 2004). Costa et al. (2004), ao estudarem bezerros recém-nascidos da raça Holandesa, relataram resultados parecidos com os obtidos no presente estudo (NBT-NE: $1 \%$ e NBT-E: 5,5\%). Porém, encontraram valores maiores nas idades mais avançadas (NBT-NE: $14 \%$ e NBT-E: $49,5 \%$ ). Peixoto et al. (2002) observaram menor capacidade oxidativa dos neutrófilos de bezerros até 30 dias quando comparados a animais de 30-90 dias de idade. Contrariando essas evidências, Amorim (2002) constatou justamente o inverso em bezerros Nelore. O número de neutrófilos redutores nos recém-nascidos diminuiu até o quinto mês de vida. Poli \& Mantelli (1974) e Menge et al. (1998) também relataram maior eficiência nas células de animais mais jovens.

Observou-se diferença significativa entre as raças quanto ao metabolismo oxidativo dos neutrófilos nas idades de 30, 90 e 120 dias para a prova do NBT-NE e aos 15, 30, 90 e 120 dias para o NBT-E (Quadro 3). A superioridade dos bezerros taurinos sobre os zebuínos (Fig.1 e 2) fica mais patente ao se provar que os primeiros exibiram, além disso, uma tendência a possuírem menor número de neutrófilos circulantes $(p=0,054)$. Apesar da atividade redutora dos neutrófilos dos bezerros da raça Limousin ter sido maior, essa diferença, no entanto, não demonstrou importância prática sobre a saúde dos bezerros nas duas raças. Isto pode ser devido ao baixo desafio imposto sob as condições de manejo extensivo, aliado ao fato de as propriedades praticarem manejos nutricional e sanitário adequados. Deve-se considerar que a ação dos neutrófilos não é a única responsável pela defesa do organismo (Tizard 2002).

Borges et al. (2001) demonstraram que a infecção com Babesia spp. e Anaplasma marginale causam aumento da atividade redutora dos neutrófilos. No entanto, utilizaram animais adultos durante o período de premunição. Os resultados do presente estudo reforçam essa evidência nos bezerros. Nas duas raças, o maior número de células redutoras do NBT a partir dos 60 dias de idade coincidiu com o aumento na contagem de linfócitos e com o maior número de bezerros naturalmente infectados por Anaplasma marginale. Até mesmo a distinção observada entre taurinos e zebuínos no percentual de neutófilos redutores aos 90 e 120 dias de idade (Fig.1 e 2) pode ter relação com a infecção pelo hemoparasita. Nessas idades o número de bezerros Nelore portadores de hemácias parasitadas diminuiu enquanto o de bezerros Limousin se manteve elevado (Quadro 2).

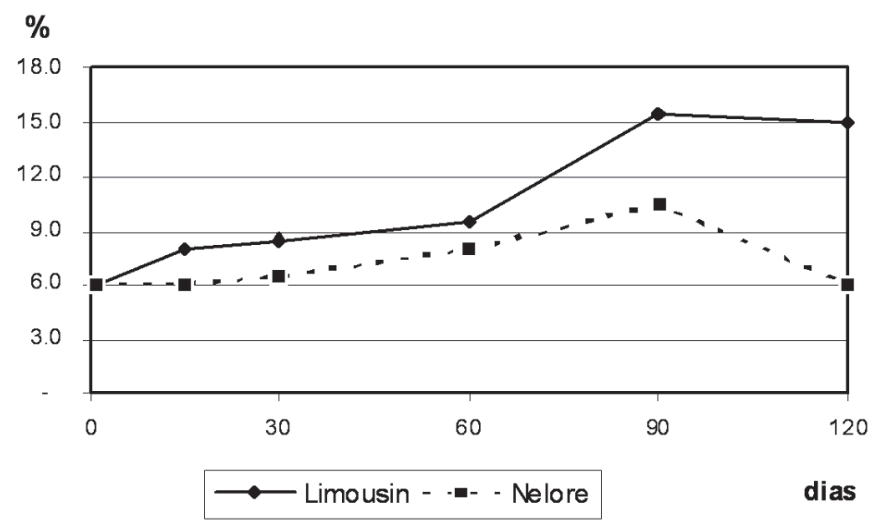

Fig.1. Porcentagem de neutrófilos redutores do tetrazólio de nitroazul na prova não estimulada (NBT-NE) em bezerros sadios das raças Nelore e Limousin nos primeiros 4 meses de vida.

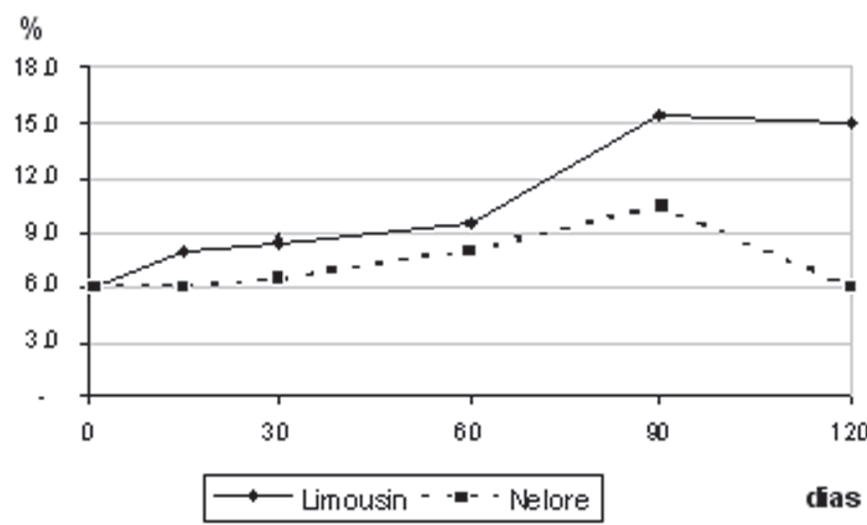

Fig.2. Porcentagem de neutrófilos redutores do tetrazólio de nitroazul na prova estimulada (NBT-E) em bezerros sadios das raças Nelore e Limousin nos primeiros 4 meses de vida. 
Durante o estudo registraram-se somente oito ocorrências de doenças. Quatro bezerros da raça Limousin e dois da raça Nelore entre 15 e 30 dias de idade apresentaram quadro de diarréia sem maiores complicações. Uma onfalopatia foi identificada em um bezerro Limousin aos 15 dias de vida, mas o processo não se agravou posteriormente. Um único bezerro da raça Limousin morreu aos 50 dias de idade provavelmente devido à infecção por hemoparasitas. No entanto, todos apresentaram valores ao teste do NBT próximos à mediana obtida para suas idades. Devido ao baixo número de animais acometidos, não é possível afirmar que o aumento de neutrófilos reativos ao NBT ocorrido a partir dos 60 dias foi causado pela ocorrência de doenças, como haviam sugerido Bednarek et al. (1998). Com exceção do único bezerro que morreu, todos os demais bezerros infectados com hemoparasitas comportaram-se como portadores assintomáticos. Nenhum deles recebeu qualquer tratamento e todos se mantiveram aparentemente sadios.

A menor capacidade oxidativa dos neutrófilos de bovinos mais jovens pode ser um fator predisponente à ocorrência de doenças. Entretanto, devem-se levar em conta outros mecanismos de defesa, como a grande quantidade de imunoglobulinas adquiridas pelo colostro, o maior número de neutrófilos circulantes e a sua maior capacidade fagocitária quando comparados a animais adultos (Hauser et al. 1986). A transferência de imunidade passiva foi bem sucedida nos bezerros estudados (Costa 2007).

Assim como Borges et al. (2001) demonstraram que a infecção por hemoparasitas pode causar aumento na capacidade oxidativa dos neutrófilos, Bednarek et al. (1998) observaram maior proporção de neutrófilos reativos em animais com broncopneumonia. No entanto, outros resultados reforçam o conceito de que o aumento da capacidade oxidativa dos neutrófilos seja fisiológico nos bezerros (Hauser et al. 1986, Peixoto et al. 2002, Costa et al. 2004). Estudos posteriores envolvendo a ocorrência de doenças são necessários para o esclarecimento da maior capacidade bactericida dos neutrófilos dos bovinos com o avançar da idade. A execução de um estudo das variações estritamente fisiológicas é difícil nas condições naturais brasileiras. A manutenção dos bezerros sob condição artificial de manejo, sem contato com carrapatos ou insetos hematófagos seria o procedimento correto para se evitar, por completo, a interferência da infecção pelos hemoparasitas nos resultados. Os valores estabelecidos nos países de clima temperado ou frio não devem ser admitidos como de referência pelos clínicos no Brasil.

Pode-se concluir que o metabolismo oxidativo dos neutrófilos de bezerros de corte se modifica com a idade, ocorrendo aumento da capacidade oxidativa ao longo dos quatro primeiros meses de vida. A infecção natural e assintomática com Anaplasma marginale contribui para a variação.

Agradecimentos.- Ao Prof. Dr. Joandes Henrique Fonteque da UDESCLages pelas orientações para a execução dos procedimentos de determinações laboratoriais. Ao engenheiro agrônomo Dr. José Renato Silva Gonçalves, responsável técnico da Fazenda Figueira e Estação Experimental Agrozootécnica da FEALQ.

\section{REFERÊNCIAS}

Adams R., Garry F.B., Aldridge B.M., Holland M.D. \& Odde K.G. 1992. Hematologic values in newborn beef calves. Am. J. Vet. Res. 53(6):944950.

Amorim R.M. 2002. Valores séricos e hepáticos de elementos minerais, atividade sérica da ceruloplasmina, hemograma, proteinograma e metabolismo oxidativo dos neutrófilos em bezerros da raça Nelore, nascidos de mães com nutrição adequada ou inadequada em cobre e zinco. Tese de Doutorado em Clínica Veterinária, Faculdade de Medicina Veterinária e Zootecnia, Universidade Estadual Paulista, Botucatu. 158p.

Baehner R.L. \& Nathan D.G. 1968. Chronic granulomatous disease. N. Engl. J. Med. 278(18):971-976.

Bednarek D., Zdzisinska B., Kondracki M., Rzeski W., Lokaj I. \& KandeferSzerszen M. 1998. Alterations in peripheral blood leukocytes functions during enzootic bronchopneumonia of calves. Effect of treatment with antibiotics and immunomodulators. Dtsch. Tierärztl. Wochenschr. 105(5):194-199.

Benesi F.J. 1992. Hematologia de bezerros recém-nascidos. Influência da asfixia neonatal, do tipo de parto e da ingestão de colostro sobre a crase sangüínea. Tese de Livre-Docência, Faculdade de Medicina Veterinária e Zootecnia, Universidade de São Paulo, São Paulo. 126p.

Biondo A.W., Lopes S.T.A., Kohayagawa A., Takahira R.K. \& Alencar N.X. 1998. Hemograma de bovinos (Bos indicus) sadios da raça Nelore no primeiro mês de vida, criados no estado de São Paulo. Ciência Rural 28(2):251-256.

Birgel Junior E.H., D’Angelino J.L., Benesi F.J. \& Birgel E.H. 2001. Valores de referência do leucograma de bovinos da raça Jersey criados no estado de São Paulo. Braz. J. Vet. Res. Anim. Sci. 38(3):136141.

Borges A.S., Melchert A., Conceição M., Kohayagawa A., Lopes R.S., Takahira R.K., Kuchembuck M.R.G., Torres L.F. \& Benine L.E. 2001. Metabolismo oxidativo de neutrófilos em bovinos (Bos taurus) durante a premunição contra Anaplasma sp. e Babesia sp. Vet. Notícias, Uberlândia, 7(1):75-79.

Ciarlini P.C., Barros C.M.Q., Lopes M.D., Kohayagawa A., Krause A. \& Laposy C.B. 1999. Leucograma, fibrinogênio e capacidade bactericida dos neutrófilos de éguas susceptíveis e resistentes à endometrites. Revta Bras. Reprod. Anim. 21(3):123-126.

Costa J.N., Peixoto A.P.C., Kohayagawa A., Ferreira A.F.M.S.C., Cassetari M.L. \& Crocci A.J. 2004. Influência do desenvolvimento etário e da suplementação com vitamina $E$ (acetato de DL-alfa-tocoferol) no metabolismo oxidativo dos neutrófilos de bovinos da raça Holandesa (Bos taurus). Braz. J. Vet. Res. Anim. Sci. 41(5):293-298.

Costa M.C. 2007. Transferência de imunidade passiva e metabolismo oxidativo dos neutrófilos em bezerros das raças Nelore e Limousin. Dissertação de Mestrado em Sanidade Animal, Universidade Estadual de Londrina, Londrina. 84p.

Curi P.R. 1998. Metodologia e Análise da Pesquisa em Ciências Biológicas. $2^{a}$ ed. Gráfica e Editora Tipomic, Botucatu. 263p.

Ebehart R.J. \& Patt J.A. 1971. Plasma cortisol concentrations in newborn calves. Am. J. Vet. Res. 32(12)1921-1927.

Fagliari J.J., Santana A.E., Lucas F.A., Campos Filho E. \& Curi P.R. 1998. Constituintes sanguíneos de bovinos recém-nascidos das raças Nelore (Bos indicus) e Holandesa (Bos taurus) e de bubalinos (Bubalus bubalis) da raça Murrah. Arq. Bras. Med. Vet. Zootec. 50(3):253-262.

Gordon P.A., Stuart J., Lee T.R., Breeze G.R. \& Pugh R.N.H. 1975. The cytocentrifuge NBT test. J. Clin. Pathol. 28(8):674-679.

Hauser M.A., Koob B.S. \& Roth J.A. 1986. Variation of neutrophil function with age in calves. Am. J. Vet. Res. 47(1):152-153.

Hoffman R.P. 1987. Diagnóstico de parasitismo veterinário. Sulina, Porto Alegre. 156p. 
Jain N.C. 1986. Schalm's Veterinary Hematology. $4^{\text {th }}$ ed. Lea and Febiger, Philadelphia. 1221p.

LaMotte G.B. \& Eberhart R.J. 1976. Blood leukocytes, neutrophil phagocytosis, and plasma corticosteroids in colostrum fed and colostrum-deprived calves. Am. J. Vet. Res. 37(10):1189-1193.

Menge C., Neufeld B., Hirt W., Schmeer N., Bauerfeind R., Baljer G. \& Wieler L.H. 1998. Compensation of preliminary blood phagocyte immaturity in the newborn calf. Vet. Immunol. Immunopathol. 62(4):309-321.

Park H.H. \& Good R.A. 1970. N.B.T. test stimulated. Lancet 19(2):616.

Peixoto A.P.C., Costa J.N., Kohayagawa A., Takahira R.K. \& Saito M.E. 2002. Hemograma e metabolismo oxidativo dos neutrófilos de bovinos da raça Holandesa preta e branca: influência dos fatores etários. Revta Bras. Saúde Prod. Anim. 3(1):16-20.
Poli G. \& Mantelli F. 1974. II test N.B.T. negli animali domestici valori normali. Clin. Vet., Milan, 97(4):241-246.

Taylor J.A. 2000. Leukocyte responses in ruminants, p.391-404. In: Feldman B.F., Zinkl J.G. \& Jain N.C. (ed.), Schalm's Veterinary Hematology. $5^{\text {th }}$ ed. Lippincott Williams and Wilkins, Philadelphia.

Tizard I.R. 2002. Imunidade no feto e no recém-nascido, p.233-246. In: (ed.), Imunologia Veterinária: uma introdução. 6aㅡ ed. Roca, São Paulo.

Yoshihara E. 2001. Estudo sorológico sobre a freqüência de anticorpos e infecção natural pelo Anaplasma marginale em vacas e bezerros da raça Nelore na região de Umuarama, Estado do Paraná, Brasil. Dissertação de Mestrado em Sanidade Animal, Universidade Estadual de Londrina, Londrina. 51p. 